\title{
Determining Appropriate Damages for Patent Infringement: An Alternative Approach
}

\author{
Michael D'Rosario \\ Department of Finance, Deakin Business School, Deakin University, Victoria, Australia \\ Email: michaeld@deakin.edu.au
}

How to cite this paper: D'Rosario, M. (2017) Determining Appropriate Damages for Patent Infringement: An Alternative Approach. Theoretical Economics Letters, 7, 295-315.

https://doi.org/10.4236/tel.2017.73023

Received: December 29, 2016

Accepted: March 13, 2017

Published: March 16, 2017

Copyright $\odot 2017$ by author and Scientific Research Publishing Inc. This work is licensed under the Creative Commons Attribution International License (CC BY 4.0).

http://creativecommons.org/licenses/by/4.0/

\section{(c) (i) Open Access}

\begin{abstract}
Determining the quantum of damages that should be afforded to an applicant when patent infringement has occurred is problematic for a number of reasons. Incorporeal works are difficult to value, and consequently certain categories of intellectual property present real challenges for the courts. This paper contends that citation information may be particularly helpful in relation to patents for a number of reasons. Citation information may afford useful insights into the level of industry uptake and the amount of subsequent innovation made possible by the patent. This insight may be particularly beneficial in situations where the courts are considering awarding additional damages. While the courts have not considered patent citation information thus far, the paper presents a number of patent citation-related metrics that may assist with the determination of patent damages.
\end{abstract}

\section{Keywords}

Patents, Litigation, Damages, Citations

\section{Introduction}

Determining appropriate damages when a patent infringement has occurred is highly problematic for a number of reasons. Intellectual works such as patents or trademarks are the incorporeal product of intellectual efforts. The more that a property is designed, constructed or suited for a special purpose, the more difference there will be in value, as measured by various criteria, and this is especially true of intangible assets and intellectual property [1]. If the valuation of an intellectual property is challenging so too is the determination of appropriate damages when an infringement has occurred. Physical properties are less difficult to value, because they are constituted by physical components to which values can be more readily assigned. For example, buildings are constituted by substrates, and motor vehicles are made up of various composites and components 
to which values can be assigned relatively easily ${ }^{1}$. The existence of primary and secondary markets for vehicle components, for example, makes it relatively straightforward to assess damages pertaining to a motor vehicle.

Incorporeal properties also create unique challenges in relation to their use. What rights are conferred to the licensee of an incorporeal work, and how can the work be employed? Framing such rights and determining the damage associated with an infringement pertaining to corporeal goods is far less challenging than in relation to incorporeal works. Russell Parr claims that there is a significant difference in the value of the full right of ownership of a corporeal good, such as a piece of physical machinery, and the right to use the good. These rights are much more difficult to define and enforce for intellectual property than for physical property [1]. Consider, for example, the purchase or licensing of a book or song in digital format, as opposed to the purchase of tangible equivalents. In relation to the former, a number of unique questions arise in relation to replication, concurrent use and sharing.

As noted by Mark Glick et al. in Intellectual Property Damages, in economics it is largely held that "ideas" differ from physical property in a number of pertinent ways. The authors contend that, like "ideas", incorporeal goods such as patents and trademarks share the same intrinsic qualities as public goods, and that in the absence of regulation they would be non-rival and non-excludable [2]. In acknowledging the critical differences in the nature of corporeal and incorporeal property, Thomas Jefferson asserted that

If nature has made any one thing less susceptible than all others of exclusive property, it is the action of the thinking power called an idea, which an individual may exclusively possess as long as he keeps it to himself; but the moment it is divulged, it forces itself into the possession of every one, and the receiver cannot dispossess himself of it. Its peculiar character, too, is that no one possesses the less, because every other possesses the whole of it. He who receives an idea from me, receives instruction himself without lessening mine; as he who lights his taper at mine, receives light without darkening me [3].

That ideas should freely spread from one to another over the globe, for the moral and mutual instruction of man, and improvement of his condition, seems to have been peculiarly and benevolently designed by nature, when she made them, like fire, expansible over all space, without lessening their density in any point, and like the air in which we breathe, move, and have our physical being, incapable of confinement or exclusive appropriation. Inventions then cannot, in nature, be a subject of property.

A number of economists assert that excludability in relation to certain incorporeal properties is necessary to ensure that those creating intellectual works are sufficiently rewarded for their efforts. Moreover, as economics shifted from

${ }^{1}$ It should be noted that this assertion makes reference to the value of the physical components, not the underlying intellectual properties that would be relevant to the construction of a home (designs) and the fabrication of an automotive vehicle (patented technologies). 
static to dynamic methods of analysis, seminal research by Robert Solow [4] and contemporary theorists like Edward Denison [5] clearly show that a large portion of annual productivity gains over time results from advances in scientific and technological knowledge.

Essentially, without the ability to prevent others from employing certain intellectual properties, there would be no incentive for innovators to engage in creative activities. Therefore, intellectual property legislation seeks to protect innovators and other creators of intellectual works from non-innovators who would hope to profit from the primary innovators' efforts. This is a Shumpeterian notion, "the proposition that the protection afforded by patents and so on is, in the conditions of a profit economy, on balance a propelling and not an inhibiting factor" [6]. As noted by Suzanne Scotchmer, "most innovators stand on the shoulders of giants, and never more so than in the current evolution of high technologies, where almost all technical progress builds on a foundation provided by earlier innovators" [7].

It is for this reason that each year, industrious individuals and institutions seek to protect their innovations through patent registration. If a national patent registration body accepts a submission, it affords the patent holder with the unique ability to employ their innovation while preventing others from accessing and exploiting the innovation, unless they secure the necessary contractual arrangements with the patent holder. The justification for this allowance emanates from two concepts relating to the labour invested in the production of the intellectual work: The idea that the intellectual work is a reflection of the creator's identity and the identity of the creator is indelibly linked to the intellectual work, and the idea that the creator should be in some way rewarded for their efforts. Neither justification in and of itself serves as a complete justification for intellectual property rights.

The patent holder may have their innovation recognised in other jurisdictions, depending on reciprocal arrangements that exist between the nation of registration and jurisdictions abroad. Intellectual property legislation seeks to find accord between the interests of the creator of the intellectual property, and other competitor(s) and society at large. The World Trade Organisation (WTO)-administered Agreement on Trade-Related Aspects of Intellectual Property Rights [TRIPS] introduced intellectual property law into trade. TRIPS outlines a set of minimum standards for intellectual property regulations that apply to all members. The agreement proscribes civil procedure frameworks to be enshrined in national law that promote efficient, timely and affordable remedies for intellectual property rights (IPR) violations. IPR enforcement should not create undue barriers, and should not enable abuse of process. Remedies for IPR violations include injunctive relief, direct compensation or the destruction of infringing material [8].

Where a violation occurs, there may need to be a determination in relation to the quantum of damages to be assigned in a civil proceeding. The courts have employed a number of approaches to determining the quantum of damages to 
assign, though as asserted, the determination of appropriate damages in infringement cases is problematic. This article considers approaches adopted by the courts and proffers an alternative method that may assist in determining appropriate damages for loss or damage, and for additional damages pursuant to Patents Act 1990 (Cth) s 122(a) [9]. While the article is written in the context of Australian jurisprudence, the findings are broadly relevant to other jurisdictions.

Pertinently, the posited method may be somewhat beneficial in establishing an innocent infringement defence. While acknowledging significant differences between certain categories of intellectual property, there is sufficient similarity between patent, design and trademark rights-particularly in relation to damages provisions-for it to be useful to consider relevant, non-patent jurisprudence when analysing patent damages. While this article primarily focuses on patents, many principles applied to patents are excerpted from the jurisprudence of other forms of IPR, such as copyright, and as such are considered in this article where applicable. The jurisprudence of potentially relevant copyright cases is also considered herein.

\section{Intellectual Property and Economic Estimation: A Precis}

Economic research pertaining to intellectual property is not a novel pursuit. However, much of the research is largely theoretical in nature, and applied research is relatively less common. Richard Posner asserts that economic analyses of intellectual property have traditionally focused on reconciling incentives for producing such property, with concerns about restricting access by granting exclusive rights to intellectual goods-that is, by "propertising" them-and thus allowing the owner to charge an access price that exceeds marginal cost [10]. While this was and continues to be a parsimonious pursuit, this orientation has resulted in a number of relevant empirical questions being set aside.

Consequentially, many common law principles and legislative pronouncements enacted in support of IPR have largely gone unnoticed in conventional economic analysis of intellectual property research. Posner notes that this is beginning to change somewhat, however. With the rise of the law and economics movement, economic analysis has begun to shift focus to more concrete and manageable issues concerning the structure and texture of the complicated pattern of common law and statutory doctrines, legal institutions and business practices relating to intellectual property [10].

Mark Glick notes that economists have played a limited role in the damages phase of patent infringement cases, asserting that this phase has largely been the domain of accountants and patent attorneys. His study argues that this is inapt, as economic theory is highly relevant to determining patent damages in cases of infringement [2]. Economic logic is particularly helpful in the analysis of intellectual property when the unique nature of different types of intellectual property (patents, designs and copyright) is acknowledged.

A number of earlier studies have considered patent damages from a law and economics perspective, and offered approaches to damages calculations. How- 
ever, there appears to be a dearth of research offering methods that may assist with judicial deliberations in relation to compensatory damages, and an even greater lack of research offering guidance in relation to additional damages assessment. Most studies employ conventional economic logic to damages analysis, with little said about the potential role of networks theory and, pertinently, patent citations.

Federico Munari provides a detailed commentary on economic methods applicable to patent damages and licensing calculations [11] [12]. The study considers a number of well-reasoned approaches to damages calculations, such as hypothetical negotiation values, adjusted royalty rates and more arbitrary rules of thumb. The paper also considers the factors established by Georgia Pacific [13]. It is noteworthy that the paper did not consider the potential role of citations in damages assessments.

Robert Reilly and Robert Schweihs consider the economic basis of the oft-cited rules of thumb employed in determining patent damages, asserting that they are not founded in economic theory, but rather are arbitrary measures that have evolved through industry averages and historical practices. The authors assert that while the rules tend to distil actual economic value drivers into a simple relationship, they may not withstand contrarian examination in a civil proceeding [14]. Meir Perez Pugatch details a number of commonly employed economic approaches to determining patent damages, such as discounted cash flow analysis and real option analysis [15]. However, there is dearth of research considering this challenge. The extant literature fails to consider the potential role of patent citation information in damages assessments.

Much of the extant patent analysis employs bibliometric techniques to analyse patent citation information. M.M.S. Karkioffers a survey of the various methods of patent citation analysis and their applications, outlining a number of technological indicators [16]. Anthony Brietzman and Mary Ellen Mogee consider the use of patent analysis in a number of scenarios, from corporate finance to securities valuation, offering several metrics that are useful in a number of situations [17]. Michael Roach and Wesley Cohen look at the validity of patent citation information as a measure of knowledge-flow, and in particular the validity of backwards citation information [18]. Employing survey-based techniques, the authors measure the dimensions of knowledge-flow from public research. Rui $\mathrm{Li}$ et al. consider the role of specific bibliometric indicators in the context of the association between patented knowledge and scientific research. "Science linkage" is a patent bibliometric indicator that is widely used to determine the association between patents and general scientific research, employing a count of the frequency of citations to scientific papers referenced in the patent. The authors assert that "science linkage is regarded as a noisy indicator because patent citation behaviour varies from inventors/applicants to examiners" [19]. In order to identify and ultimately reduce this noise, we analysed the different citing motivations of examiners and inventors/applicants. We built four hypotheses based on our study of patent law, the unique economic nature of a patent and a patent 
citation's market effect.

A significant number of studies have considered the relationship between patent citations and patent value to determine the value of new technologies and innovations as well as existing patents. Bhaven Sampat and Arvids Ziedonis employ data from two major research institutions to examine the association between patent citations and the likelihood of licensing. The authors' results indicate that citations are significantly related to the probability of a patent being licensed [20].

Harhoff et al. employ patent citation information and bibliometric information to determine a patent's value. The authors claim that the number of citations a patent receives and the references included in the patent are positively correlated with patent value. Interestingly, the authors assert that non-patent references, i.e. references to non-patent research and literature, only offer insight into the value of pharmaceutical and chemical patents, specifically. This information is not beneficial in determining the value of patents in other technical disciplines. Patent citation information remains most pertinent to determining value in all situations, while non-patent references offer some benefit to the determination of value in very limited circumstances. Moreover, the authors note that patents which are upheld after opposition and annulment procedures are found to be particularly valuable, as are patents subsumed within large patent families [21] [22].

The work of Browyn Hall, Adam Jaffe and Manual Trajtenberg is particularly relevant to the present study. The authors framed a comprehensive dataset pertaining to the patent activity of 4800 US firms. The author's seminal study ranked amongst the first to employ such a large patent dataset to explore the association between patent citations and patent value. The authors consider the impact of research and development, patents and citation-weighted patents to determine the Brainard/Tobin's $\mathrm{Q}^{2}$, a measure of a firm's asset base relative to its replacement value. The authors found that citation-weighted patent stocks are more highly correlated with market value than patent stocks alone (unadjusted). The authors postulate that this is due to the high value placed on highly cited patents. The claim presented here is an extension of the postulate put forward in the Hall et al. study. Consistent with the extant literature, this study claims that patent citations are associated with patent value. Hall et al. explored the benefit of citation weighting for determining if patent quality. The authors concluded that patent quality as measured by citation counts, are more highly correlated with firm value than unweighted patent counts [23].

The claim presented here is an extension of the postulate put forward in the Hall et al. study. Consistent with the extant literature ${ }^{3}$, this study claims that patent citations are associated with patent value. Hall et al. explored the benefit

${ }^{2}[\mathrm{t}]$ he numerator, is the market valuation: the going price in the market for exchanging existing assets. The other, the denominator, is the replacement or reproduction cost: the price in the market for the newly produced commodities. We believe that this ratio has considerable macroeconomic significance and usefulness, as the nexus between financial markets and markets for goods and services' [24].

${ }^{3}$ See Hall et al. [23], Sampat and Ziedonis [20], Harhoff et al. [22]. 
of citation weighting for determining if patent quality. The authors concluded that patent quality as measured by citation counts, are more highly correlated with firm value than unweighted patent counts.

Considering the obvious association between patent value and patent royalties, the present study seeks to assert the usefulness of citation metrics in damages analysis, and in particular scenarios where additional damages are to be awarded. The study defines a series of adjusted and unadjusted patent metrics that serve to offer insight into patent awareness in the industry, and potentially the flagrancy of an infringing action.

\section{The Australian Framework}

Intellectual property infringement is a breach of a statutory duty rather than a contractual duty. The Australian framework affords protections not just to the patent holder locally, but to patent holders internationally by virtue of a number of bilateral and multi-lateral agreements. Australia is a signatory to the TRIPS agreement. The Australia-US free trade agreement sought to promote greater harmonisation of Australia's approach to intellectual property with that of the United States.

The Australian patent system is somewhat unique in its recognition of "innovation patents", a form of patent that affords the holder the same privileges as a standard patent, but over a shorter duration and for a limited number of claims. This form of patent was conceived to afford small to medium-sized entities a mechanism though which they can protect their innovations, albeit with greater restrictions.

The Australian courts have a broad set of powers for dealing with intellectual property infringement, with a number of remedies available to address intellectual property infringements. Orders include pre-trial and or preliminary discovery orders, civil search orders, seizure orders and interim injunctions. Further orders include declarations (i.e. infringement versus non-infringement in relation to ownership and granting relief pursuant to unjustifiable threats), orders for the payment of damages and orders for the payment of an account of profits. The noted orders are straightforward, often necessitating the temporary or permanent cessation of an activity or a search, seizure or corrective action. The determination of appropriate damages is not so straightforward, and requires astute consideration.

\section{The Nature of Patent Damages}

Patent infringement is tortious in nature and the assignment of damages is compensatory. The assignment of damages pertains to the provision of pecuniary or monetary damages. An action does not necessitate proof of damage. Rather, the activity which necessitates the provision of damages is the infringing activity of the defendant. The defendant must be acting without the authority, license or consent of the patent holder. Damages are assigned because the action of the defendant infringed upon the statutory monopoly of the patent holder. 
Damages seek to return the patent holder to the position that they would be in had the infringing act not occurred, notwithstanding the statutory basis (as opposed to common law underpinnings) of the damages assignment, as asserted infringement is considered to be a tort.

There are no precisely defined rules to which the courts must adhere when determining assigned damages, and the courts have adopted several approaches to calculating damages. The courts may be guided by the intellectual property holder's loss of profit, the presumed licence fee or how the infringement has been prejudicial to the intellectual property holder's interests. The assigned quantum of damages is a function of the loss brought about by the infringing act, or the extent to which the intellectual property has declined in worth as a result of the infringing act.

As per Patents Act 1990 (Cth) s 122(1), "The relief which a court may grant for infringement of a patent includes an injunction (subject to such terms, if any as the court thinks fit) and, at the option of the plaintiff, either damages or an account of profits" [25]. As such, the assignment of damages and injunctive relief are not mutually exclusive remedies. There is no constraint on the court to provide both injunctive relief to the patent holder and to require the payment of damages to the patent holder. While the statutory language may suggest that compensation is optional, this is not the case. Pursuant to Review Australia Pty Ltd $v$ Innovative Lifestyle Investments Pty Ltd, when an infringement has damaged the plaintiff, the court should award damages [26]. The court cannot, however, order the payment of damages and an account of profits. This is clarified by Windeyer J in Colbeam Palmer Ltd v Stock Affiliates Pty Ltd:

The two computations can obviously yield different results, for a plaintiff's loss is not to be measured by the defendant's gain, nor a defendant's gain by the plaintiff's loss. Either may be greater, or less, than the other [27].

Pursuant to the Intellectual Property Laws Amendment Act 2006 (Cth), the courts may also now award additional damages when the infringement is said to be flagrant. Prior to this Act, the patentee/applicant's ${ }^{4}$ available remedies were limited to an account of profits or compensatory damages for incurred losses. The amendment brought a degree of uniformity to Australian intellectual property legislation and fortifies the rights of patentees. The Act is now consistent with the Designs Act 2013(Cth) and Copyrights Acts 1968 (Cth), affording the courts the ability to assign significant additional damages. The wording is such that the courts may award additional damages even where there is not significant evidence of damage.

As per the Intellectual Property Laws Amendment Act 2006 (Cth) sch 5, the Patents Act 1990 (Cth) presently grants the court the ability to assign additional damages. Consider s 122(1)(a):

A court may include an additional amount in an assessment of damages for an

${ }^{4} \mathrm{~A}$ non-patentee/patent holder may receive monetary compensation where an exclusive licensing arrangement exists. 
infringement of a patent, if the court considers it appropriate to do so having regard to: (a) the flagrancy of the infringement; and (b) the need to deter similar infringements of patents; and (c) the conduct of the party that infringed the patent that occurred: i) after the act constituting the infringement; or ii) after that party was informed that it had allegedly infringed; iii) the patent; and (d) any benefit shown to have accrued to that party because of the infringement; and (e) all other relevant matters.

Additional damages cannot be awarded merely by establishing that copying is occurring. If the defendant unsuccessfully seeks to establish the invalidity of a patent, this is also not in itself enough to be granted additional damages [9]. While some foreign jurisdictions allow the patent holder to procure unjust enrichment damages (profits made by the infringer due to infringement), this remedy is not available in Australia.

\section{Conventional Approaches to Assessing Damages}

Damages are assigned to address losses caused by the defendant's infringement on the patent holder's statutory monopoly. Additional damages may be assigned pursuant to Patents Act 1990 (Cth) s 122(a), with the relevant jurisprudential principles from copyright considered relevant to patent cases [28]. The courts have not adopted one particular method to determine appropriate damages, though they have frequently adopted the lost-sales approach and the license-fee approach. Pertinently, there appears to be little guidance in relation to granting additional damages pursuant to the Patents Acts 1990 (Cth) s 122(1)(a) for patent infringement, notwithstanding Zetco Pty Ltd $v$ Austworld Commodities Pty Ltd.Zetco will be considered in greater detail subsequently [29].

\subsection{The Loss-of-Sales Approach}

The lost-sales approach is problematic for the plaintiff, given that the sale of an infringing unit does not in itself equal one unit of lost sales for the plaintiff. In Elwood Clothing Pty Ltd $v$ Cotton On Clothing Pty Ltd, the appellant sought compensatory damages employing the lost-sales method. The plaintiff adopted a probabilistic approach to establish its damages claim based on average sales figures, making adjustments to account for what sales figures would have been had the respondent not been operating in the same market. This figure was then applied to a three-year sales window. This approach was rejected on the grounds that the probabilistic approach was not consistent with the presented facts [30].

Gordon J noted that one of the t-shirts in question was an updated version of an earlier design marketed by the company, noting that the original design only sold for a mere 18 months, a substantially shorter period than the three years used in the claim. Gordon J noted the following steps in relation to the calculation of compensatory damages. It may be assumed that, firstly, the respondent sought to capture the applicant's market share; secondly, that the respondent's additional sales should be equated to the applicant's lost sales; and thirdly, that when making assumptions about applicant's lost sales, it must be acknowledged 
that not all of the respondent sales would translate into applicant sales. Therefore, the respondent's sales must be discounted by some factor to acknowledge this imperfect correlation.

Elwood presented the courts with a number of challenges, pertinently that the applicant failed to provide any expert to assist with the determination of an appropriate discount factor to facilitate the determination of damages, nor was any evidence forthcoming that could assist in this regard. Gordon J made clear that such guidance would have been of particular help in determining the quantum of damages to assign. While the determination of appropriate damages is an inexact science and is expected to rely on some conjecture, it is apparent that any potential guidance by way of evidence or a sound estimation methodology would be advantageous.

\subsection{The License-Fee Approach}

The licence-fee approach seeks to link compensation to a theoretical or actual licence fee value that would have been paid by the infringer were they to legitimately secure the contested intellectual property. Given that this approach seeks to link the quantum of infringing goods or services to the cost associated with lawfully employing the intellectual property, at face value it appears more reconcilable with reality and less subject to arbitrary estimation. Challenges do arise, however, where there are not existing licence arrangements in place from which a licence value can be derived, therein necessitating potentially arbitrary estimation.

\section{Calculating Additional/Exemplary Damages}

The interpretation of the Patents Act 1990 (Cth) [9] may be guided by the relevant jurisprudence associated with the corresponding provisions in Copyright Act 1968 (Cth) [31]. While Zetco has significantly aided the interpretation of the exemplary damages provisions in the Patents Act 1990 (Cth), damages were not awarded, thus limiting the inferential benefit of the case in relation to the economic/calculative methods to be adopted in determining additional patent damages. In her summary judgment, Bennett $J$ inferred that the relevant jurisprudence from copyright law and its analogous provisions would be relevant to the determination of additional damages. As such, the relevant jurisprudence pertaining to copyright is considered in this article.

Copyright provisions have been extensively employed by a number of applicants to procure additional compensation from infringing parties. The Act has been referenced to procure additional damages beyond the quantum received for compensation in relation to damages sustained. Additional damages have generally only been awarded in copyright cases where more than a basic infringement has occurred-in effect, there must be more than mere replication.

Several basic considerations should be deliberated when determining whether the conduct of the infringer represents more than just a basic act of infringement. These considerations are relevant to determining the plausibility of addi- 
tional damages in copyright proceedings. The first consideration relates to the flagrancy of the infringing action, the second relates to the deterrence motives of the court and the third relates to the conduct of the infringer.

\subsection{The Flagrancy of the Infringer's Action}

Where an infringer genuinely holds the position that the copyright does not exist, the infringing conduct cannot be said to be flagrant. Where the infringer's conduct has been established as not in good faith, deceitful and potentially calculated, this may support the assignment of additional damages.

\subsection{Punitive Damages/Deterrence Approach}

Where copyright infringement is widespread, the courts have frequently adopted a punitive damages approach whereby additional damages assigned may well exceed the quintal of actual damages by a significant margin.

\subsection{Conduct of the Infringing Party}

Additional damages have been awarded in copyright infringement cases where an infringer has attempted to conceal their behaviour. Damages beyond basic compensatory damages have also been granted when the infringer has engaged in reciprocal action against the patentee/applicant in response to being made aware of their infringing action.

\subsection{Non-Quantifiable Benefits to the Infringing Party}

In copyright cases, the courts have considered benefits gained by the infringing party that cannot easily be accounted for. All things being equal, many of the non-quantifiable (or not easily quantifiable) benefits of patent infringement may in fact be greater than the benefits associated with copyright infringement, given the associated patents' "network effect". This network effect distinction is considered in greater detail below.

\section{Assessing the Innovation Impact Factor}

It would appear that the courts' approaches to assessing patent damages have largely been sound. However, as noted by Gordon J in Elwood, guidance, expert opinion and sound estimation approaches are particularly helpful in determining appropriate damages. The courts have tended to adopt similar approaches to both copyright and patents, which is somewhat puzzling given the different qualities associated with each. This article claims that citation data may be particularly helpful in determining damages, and with establishing innocent defences during patent infringement proceedings.

\section{Patents as Networked Intellectual Works}

Unlike other intellectual property, such as a copyrighted literary work, new patents often deeply rely on prior patents and build or extend on such intellectual works. While a literary work may cite relevant past literature, it is likely to re- 
main a coherent piece of writing, absent of the cited works. Many patents, however, are based on, linked to or heavily derive from other cited patents. This makes many new patents somewhat reliant on earlier patents. For instance, a new telephone patent might rely heavily on earlier screen-related patents. The later patent might be non-functional without the earlier patent. This makes a collection of patents markedly different from other intellectual property agglomerations.

Consider, for example, the difference between this set of relations and the associations between trademarks. One trademark may be influenced by earlier trademarks, but is not rendered dysfunctional without the earlier trademark. Trademarks are more consistent with artistic works than pieces of "unique" innovation.

As such, related patents held by a firm afford significant benefits. Related patents extend a firm's reach in a given aspect of innovation, and make it more challenging for newcomers to co-opt or copy the incumbents' inventive works. In high-technology industries in particular, the aggregation of related patents is critical to a firm's success and to maintaining its incumbency.

In simple economic terms, the sum of the parts is less than the value of the constituent components as a whole. As such, unlike other forms of intellectual property, patents evidence characteristics that are akin to network-oriented goods.

Consider a simple example involving three firms: A, B and C. Firm A is the incumbent and possesses two essential LED display patents, firm $\mathrm{B}$ is a recent innovator possessing one LED display patent and firm $C$ is a new entrant possessing no new inventive patents relating to LED displays. Firm A is capable of producing current-generation LED screens without licensing and third-party patents, given their possession of the two essential patents. Firm B has the potential to produce a next-generation screen, but must first license or acquire essential intellectual properties from firm A. Firm $\mathrm{C}$ can only join the market once it has secured the necessary IP from firm A, and potentially from firm B. As such, firm B's intellectual property is only valuable to the firm to the extent that it can secure related intellectual property (Figure 1).

Compare this scenario with a piece of copyrighted work, such as a literary work. While a copyrighted novel, for example, might influence later novels, it is self-evident that there is far less interdependence between copyrighted works than related patents. Furthermore, copyrighted works and trademarks do not

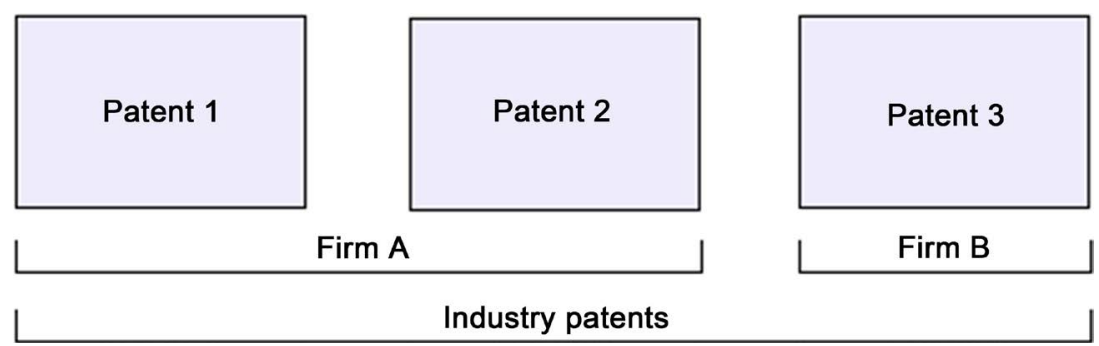

Figure 1. Patent portfolios. 
evidence the same extensible qualities as patents.

As such, the evaluation of patents and patent clusters may benefit from network-effects research. Essentially, a network effect is the benefit associated with network-based goods, where the size of the network benefit grows for all users and the user base increases in size. Margolis and Liebowitz offer a worthwhile thesis into the nature of networks [32]. The relevant literature has largely focused on physical networks, such as rail or telecommunications, and nonphysical networks like email. While patents are not networked goods under each of the conventional definitions, unlike other types of intellectual property, patents appear to evidence these rather unique network characteristics. These characteristics have been described as both network externalities and network effects.

These matters have been conjectured in economics literature since Schumpeter, but network theories have not previously been ascribed to patents [33]. The discussion of networks theory remains pertinent to patent clusters, notwithstanding the fact that they do not function as a literal network (telecommunications networks like voice telephony or the Internet, for example, are literal networks in the sense that they literally connect individuals).

This delineation is not appropriate for non-literal networks, such as the supporters of a standard in technology or software. Examples of such non-literal or "virtual" networks include Linux users or PHP Internet developers, who support each other by furthering their respective platforms, though they are not directly connected to each other. Patents are not dissimilar to non-literal networks, and are perhaps best described as intellectual networks of intangible properties. The value of any given extensible patent is enhanced by the creation of a latter patent that is reliant on the former.

Telecommunications networks are said to confer network effects rather than traditional economic externalities, in that the economic effect of the network subscription is said to be internalised, and as such would be inaccurately described as an externality in the traditional sense. Moreover, the connotation of an externality in general economic theory is associated with a market failure; to assign such a definition to a network effect would be inapt. Patent clusters could be said to confer a network benefit to the related parties, with the value of each patent in the cluster increasing with the addition of a new, related patent.

While patents pools are not true (or literal) networks, they share many of the same characteristics of network-oriented goods. They are likely to afford more value when held collectively rather than individually, and will afford the holder a pecuniary network effect benefit.

\section{Patents and Options Theory}

This quality arguably makes it more difficult to determine the value of a patent as opposed to other incorporeal works. It should be acknowledged that a patent's value is not merely a function of its direct application, but also of the indirect applications that make it possible. An antecedent patent (defined herein as a patent that is cited in subsequent patents) is essentially a real option that affords 
the user the opportunity to access further innovation ${ }^{5}$.

This should be taken into consideration when valuing the patent, and is critical when determining appropriate damages for patent infringement. A patent's value is consequential to its intrinsic valuation and the option values that it provides. This makes patent citation information useful when determining value, because in the simplest sense, the patent's value is arguably constituted by a "use" component and an "option(s)" component. While there are numerous additional tactical and strategic applications for patents that could be employed in determining intellectual property value, these alternative applications are of little consequence when determining an intellectual work's value for the purposes of a civil damages proceeding ${ }^{6}$.

Additionally, the courts' preferred methods for damage assessment (license fee and loss of sales) support the conclusion that tactical and strategic value measures are of little relevance. Citation information may yield powerful and compelling insights into the patent option value. The obvious corollary is that such information may be useful to the determination of damages.

\section{Patent Citations and Their Potential Role in Damages Assessment}

Patent citations are highly relevant to any proceedings related to contested patents; however, civil proceedings tend to give little if any credence to this important factor. In Zetco, patent citation data was not presented by either of the litigants. Considering all relevant Australian jurisprudence, there does not appear to be a single occasion where patent citations were considered. Given that an analogous metric for copyright does not exist, the noted approach is only applicable to patent cases. This article asserts that citation counts should be afforded greater attention and may assist with the determination of damages, and in particular additional damages ${ }^{7}$.

This notwithstanding, it is without question that a particular innovation may be highly beneficial but evidence a low citation rate. However, it must be acknowledged that the citation count is highly relevant for several critical reasons. The larger the number of citations that reference the antecedent patent, the larger the number of options it confers.

A high citation count a priori suggests that the patent has resulted in further

${ }^{5}$ This is because the latter patent is dependent upon the former, to enable the exploitation of the latter.

${ }^{6}$ Clearly, the courts will not consider such valuations as the strategic litigation value of a patent, for example (strategic litigation being defined as when a patent may afford the patent holder greater value in litigation as a tool to block the release of rival technology and gain some strategic advantage).

${ }^{7}$ Where patents are part of an industry-standard framework and are made available on fair, reasonable and non-discriminatory terms (FRAND), it is highly likely that they will be more frequently cited. This is an empirical question that cannot be answered at this point, but prima facie standards essential patents appear to present some challenges to the posited patent citation methods. This is of little consequence, given that standards essential patents are less likely to be the subject of litigation, and where litigation does occur, determining appropriate damages or licensing fees is less problematic than with non-standard essential patents. Non-standards essential patents that are deemed desirable to an industry and later innovators will evidence higher citation counts. 
innovation. If latter innovations cite former innovations, clearly the latter innovation owes its utility in part to the former. These assertions are consistent with the extant empirical literature. Tuomo Nikulainen et al. assess the potential of using patent statistics in predicting the future sales revenues and in determining the present value of a company active in science-based industries. The authors employ citation weighted patent counts rather than the simple count figure. It is the authors' contention that this approach better accommodates patent heterogeneity. The study identified that citation weighted counts were more strongly associated with firm value than patents alone [34]. Christian Ghiglino and Nicole Kuschyy assert that the process of new idea being generated and consequently patent generation is a Poisson process. New ideas build on existing ones and a successful new idea needs to cite these parental ideas. The parent needs to be useful as a building block of the new idea. In fact, typically many existing ideas can be chosen as a parent. The authors' assert that the possibility of an idea being used as a parent is dependent on the breadth of applicability [25].

High patent counts suggest broad levels of industry awareness. Where a patent is cited by a large number of firms, it is likely to confer a greater network benefit when employed. The following are a number of patent citation metrics (herewith patent metrics) that may be useful when the courts are deliberating appropriate damages. Consistent with the extant literature, there may be instances where the citation counts must be adjusted to reflect industry differences, and or potential issues associated with high rates of self-citation. The following metrics seek to account for patent heterogeneity and citation frequencies to afford members of the judiciary with a set of objective methods for patent assessment, and in particular additional damages determinations.

1) [Total number of firms citing (contested) patent] = Firm citation count (FSC)

The firm citation count (FSC) may be a useful metric when the courts are deliberating on whether an industry is broadly aware of the patent's existence. The FSC offers an objective measure of industry awareness beyond the existence of royalty payments, or when the contested patent is not the basis for any existing royalty program.

\section{2) [Total number of patent citations] = Patent citation count (PSC)}

The patent citation count is arguably the simplest metric to calculate and interpret, and as such may provide the most useful guidance for the courts. All things being equal, the larger the citation count, the greater the influence of the innovation on latter innovations. However, in some instances this metric may serve as a noisy indicator, given potential issues associated with self-citations.

$$
\text { 3) }\left[\frac{\text { Total number of patent citations }}{\text { Average number of catagory citations }}\right]=\text { IIR }
$$

The innovation impact ratio (IIR) provides a capture of the relative innovation impact of the patent in question, and other patents in the same family or category. As such, it provides worthwhile insight into this patent's relative standing when set against other patents in the same category. The application of 
this ratio may be problematic in certain industries and under certain conditions, particularly where the citation variance between patents in the same category is large. Under such conditions, an adjusted measure accommodating high intra-category citation variance may be worthwhile. The latter IIRs detailed below accommodate this challenge.

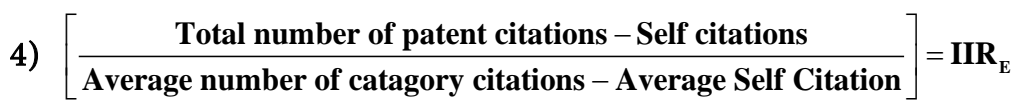

A potential challenge associated with the application of patent metrics in determining whether the assignment of damages is appropriate is the impact of firms extensively citing their own patents. This is not disingenuous behaviour, but rather the logical outcome of firms devoting time and resources to research in a given patent category. This challenge can be accommodated somewhat by accounting for self-citations. However, it must be acknowledged that under certain conditions such adjustment would be inapt, particularly where the self-citing firm is acknowledged as an industry leader. Expert judgment must be used to determine whether such adjustment is necessary.

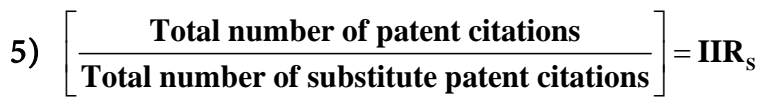

The IIRs approach involves matching the contested patent with a substitute patent where possible. This approach addresses an intra-category variance that is present in the citation counts as a result of significant differences in the underlying categories. This approach results in the determination of a ratio score that indicates whether the citation count of the contested patent is substantially greater than a potentially substitutable patent. Expert witness scrutiny and guidance will be particularly necessary, for the selection of a substitutable patent.

Adjustments to each of these metrics may be necessary given the unique structure of the Australian patents system, which allows for the registration of both standard and innovation patents. Where the citation count includes innovation and standard patents, the count may be adjusted to reflect the distinction between each. The innovation patent count may be discounted based on the critical structural distinction between each category of patents and the years of assignment.

There are two further matters consequential to this collection of approaches that must be accounted for and dealt with directly so as to acknowledge the potentially deleterious impacts of these approaches should such consequential incentives not be acknowledged. The first consequence of this approach relates to the relationship between patent citations and time; all things being equal a given patent will garner more citations the longer the patent is in circulation. Where damages are based in part on citation counts as is the case with the posited approach it might be quite rightly argued that patentees have a potentially disingenuous or in the extreme, perverse motivation to not sue for infringement at the point at which they suspect the infringement occurring, but rather to wait until some later date to pursue litigation under s.120(4) where this is identified as a potential occurrence denoted methods can be adjusted to measure average 
annual citations rather than using aggregated counts alone. This ensures that this potentially deleterious motivation is ameliorated.

A corollary to this assertion is that a patentee will receive a greater level of compensation if an infringement occurs closer to the patents end of duration rather than at the beginning, notwithstanding the quality of the patent. This is not a material concern in and of itself for two key reasons. Firstly, where a citation count increases through time, it is broadly indicative of or a proxy for patent awareness. Subsequent citations seek to account for earlier innovation offering either a level of extensibility or differentiation. Secondly the quality of an innovation is not determined principally by its initial utility, but rather by virtue of its dynamic utility. In lay terms, an innovation may be of little value initially by virtue of the availability or existence of key proximate or enabling technologies that only come into existence after the formulation of the initial innovation. The subsequent enabling technologies may greatly enhance the value of the initial innovation. As such the utility of the patent may change through time and therein so to its value. Neither the patents utility nor its value exist in isolation of convergent and divergent technologies that are formulated through time. Moreover, it should be noted that the process of arriving at the citation list included within a patent with pertinently involves applicant, legal advocate and the patent reviewer; apparently does generate appropriate incentive to have all relevant patents appropriately cited and only those deemed appropriate [23].

The second consequence of the posited approaches is that certain categories of patent such as standard essential patents will always procure more as a result of infringement than patents that are not as important to a given technology. This is a reasonable assumption given that SEP's are cited more frequently because many innovations particularly highly technical innovations must clarify their association with a given standard or set of standards. This is not in and of itself a poor consequence. I would offer that with respect to standards essential patents that there are two schools of thought. It might be argued that the additional quantum is justified by virtue of the technologies being of immense importance. The alternative school of thought would suggest that such patents may not in fact afford greater utility than nonstandard essential patents and as such don't warrant a greater quantum of compensation. With respect to SEP's, it is asserted herein that they should be treated as a unique subset of patents and treated as they are presently treated under prevailing international jurisprudence relating to SEP's involving standardised penalties based on existed licencing fees. As such, each key consequence of the noted methodologies can be addressed as long as the judicial process acknowledges the nature of the patent.

\section{Compensatory Damages, Additional Damages and the Use of the Patent Metrics}

It is highly likely that patent citation information would be most useful when a determination of additional damages is required. Patent citation metrics appear to be useful in determining the flagrancy of a given infringing act, and as such 
may be beneficial to proceedings where the issue of flagrancy is to be considered by the courts. While there is little relevant Australian jurisprudence dealing with these matters, notwithstanding Zetco, it would a priori appear that citation data would aid in determining the flagrancy of a given infringement, as it would establish the broad acceptance of a given patent and how the patent has been employed by other industry participants, whether as a source of motivation for subsequent innovation or as part of more extensible frameworks.

Citation count information could conceivably be employed in a number of ways to determine an appropriate quantum of additional damages to assign when the infringing act necessitates additional damages. Conceivable applications include using the patent citation data as weighting metrics to determine a multiplier factor to be assigned to the quantum of compensatory damages.

$$
\text { Additional damages }=\left[\left[D \times \frac{T C C}{A C C}\right]-D\right]
$$

Where $D$ is the quantum of compensatory damages, $T C C$ is the total citation count of the contested patent and $A C C$ is the average patent count within the patent category, where each count is adjusted for innovation patents. Such an approach affords a twofold benefit. Firstly, the approach captures the network benefit procured by the infringing party by capturing the significant downstream innovations that the infringing party could have exploited by virtue of their infringing act. The flagrancy of the act is reflected in the metric to the extent that the metric reflects the overall acceptance of the patent in a given industry. There are a number of challenges associated with adopting such an approach. The most obvious is associated with determining a mutually agreeable method to assess average citation counts. It is self-evident that each litigant will have dichotomous preferences, where one party will favour a broader or narrower scope depending on its impact on the resultant average.

Alternatively, a less formulaic application of the patent citation count could be adopted. The citation information could merely be used as a further piece of guidance when a determination of additional damages is required. Adopting a less formulaic approach and merely using the citation information for guidance would be far less contentious than the former approach, but would diminish the objectivity of the approach. If used as a guidance tool alone, the metric would necessitate a deeper understanding of the patent category. Those tasked with the duty of determining appropriate damages or the flagrancy of a given infringing act would be left with a less effectual judicial tool, but nonetheless still be in a better position that in the absence of such guidance.

\section{Conclusions}

This article asserts that determining the appropriate quantum of damages when a patent infringement has occurred is a genuine challenge for the courts. The intention of this article was to stimulate debate in relation to potential approaches that could be adopted in determining compensatory and additional damages. This article has posited a number of potentially viable metrics that may serve as 
guidance in determining compensatory damages, and additional damages in particular. While there are a number of inherent limitations to the noted approaches, they represent a viable first iteration in this complex debate. Moreover, they may be seen as simple and permissive tools that, in their simplest form as unadjusted citation counts, may improve judicial determinations of damages without bringing undue complexity into the decision-making process. As such, a critical contribution of this paper is its focus on offering viable and practical methodologies that may assist judicial determinations.

The benefits of such citation count information may be greatest in relation to additional damages determinations. Furthermore, such guidance information and metrics may be particularly apt in relation to innocent infringement defences. Given the need for brevity, this paper did not consider this matter, but it constitutes an important area for future research.

Future research into economically founded methodologies for the determination of infringement and/or additional and compensatory damages will benefit from the research conducted herein. Moreover, it is hoped that this first iteration in this critical debate will result in the germination of further ideas and advance debate in relation to these critical issues.

\section{References}

[1] Parr, R.L. and Gordon, V.S. (2011) Intellectual Property: Valuation, Exploitation and Infringement Damages 2011 Cumulative Supplement, Wiley, Hoboken.

[2] Glick, M.A., Lara, A.R. and Hoffman, R. (2003) Intellectual Property Damages: Guidelines and Analysis. John Wiley \& Sons, Inc., Hoboken.

[3] Jefferson, T. (1905) The Founders' Constitution Volume 3, Article 1, Section 8, Clause 8, Document 12. In: Lipscomb, A.A. and Albert, E., Eds., The Writings of Thomas Jefferson, Thomas Jefferson Memorial Association, Washington DC.

[4] Solow, R.M. (1957) Technical Change and the Aggregate Production Function. Review of Economics and Statistics, 39, 312-320. https://doi.org/10.2307/1926047

[5] Denison, E.F. (1985) Trends in American Economic Growth, 1929-1982. Brookings Institute, Washington DC.

[6] Schumpeter, J.A. (1947) Capitalism, Socialism and Democracy. Harper \& Brothers Publishers, New York.

[7] Scotchmer, S. (1991) Standing on the Shoulders of Giants: Cumulative Research and the Patent Law. Journal of Economic Perspectives, 5, 29-41. https://doi.org/10.1257/jep.5.1.29

[8] Agreement on Trade-Related Aspects of Intellectual Property Rights. Signed 15 April 1994, 1869 UNTS 299 (Entered into Force 1 January 1995).

[9] Patents Act 1990. (Cth)

[10] Posner, R.A. (2005) Intellectual Property: The Law and Economics Approach. Journal of Economic Perspectives, 19, 57-73. https://doi.org/10.1257/0895330054048704

[11] Munari, F. and Raffaele, O. (2001) The Economic Valuation of Patents Methods and Applications. Edward Elgar Publishing, Cheltenham.

[12] Munari, F., Maria, C.O. and Laura, T. (2011) Patent-Backed Finance. In: Munari, F. and Raffaele, O., Eds., The Economic Valuation of Patents: Methods and Applica- 
tions, Edward Elgar Publishing, Cheltenham, 309-336. https://doi.org/10.4337/9780857936516.00020

[13] Georgia-Pacific Corp. v United States Plywood Corp. 318 F Supp 1116, 6 USPQ 235 (SD NY 1970).

[14] Reilly, R.F. and Schweihs, R.P. (1999) Valuing Intangible Assets. McGraw, New York.

[15] Pugatch, M.P. (2006) The Intellectual Property Debate: Perspectives from Law, Economics and Political Economy. Edward Elgar Publishing, Cheltenham. https://doi.org/10.4337/9781847201782

[16] Karki, M.M.S. (1991) Patent Citation Analysis: A Policy Analysis Tool. World Patent Information, 19, 269-272. https://doi.org/10.1016/S0172-2190(97)00033-1

[17] Breitzman, A.F. and Mogee, M.E. (2002) The Many Applications of Patent Analysis. Journal of Information Science, 28, 187-205. https://doi.org/10.1177/016555150202800302

[18] Roach, M. and Wesley, M.C. (2013) Lens or Prism? Patent Citations as a Measure of Knowledge Flows from Public Research. Management Science, 59, 504-525. https://doi.org/10.1287/mnsc.1120.1644

[19] Li, R., et al. (2014) Patent Citation Analysis: Calculating Science Linkage Based on Citing Motivation. Journal of the Association for Information Science and Technology, 65, 1007-1017. https://doi.org/10.1002/asi.23054

[20] Sampat, B.N. and Arvids, Z. (2004) Patent Citations and the Economic Value of Patents. In: Moed, H.F., Glänzel, W. and Schmoch, U., Eds., The Handbook of Quantitative Science and Technology Research, Springer, Dordrecht, 277-298.

[21] Hegde, D. and Bhaven, N.S. (2009) Applicant Citations, Examiner Citations, and the Private Value of Patents. Economics Letters, 5, 287-289. https://doi.org/10.1016/j.econlet.2009.08.019

[22] Harhoff, D., Frederic, M.S. and Katrin, V. (2003) Citations, Family Size, Opposition and the Value of Patent Rights. Research Policy, 32, 1343-1363.

https://doi.org/10.1016/S0048-7333(02)00124-5

[23] Hall, B.H., Adam, B.J. and Manuel, T. (2000) Market Value and Patent Citations: A First Look. Working Paper 7741, The National Bureau of Economic Research, Cambridge. https://doi.org/10.3386/w7741

[24] Tobin, J. and Brainard, W.C. (1977) Asset Markets and the Cost of Capital. In: Fellner, W., Balassa, B.A. and Nelson, R.R., Eds., Economic Progress, Private Values and Public Policy, Essays in Honor of William Fellner, North-Holland Publishing Company, Amsterdam, 235-262.

[25] Ghiglino, C. and Nicole, K. (2010) Are Patent Citations Driven by Quality? 692.

[26] Review Australia Pty Ltd. v Innovative Lifestyle Investments Pty Ltd. 75 IPR 289, 2008.

[27] Colbeam Palmer Ltd. v Stock Affiliates Pty Ltd. 122 CLR 25, 1968.

[28] McGuire, C.C. (1999) Simulation Modeling in Forensic Economics: The Example of Reasonable Royalty Negotiations. Litigation Economics Digest, 4, 15-29.

[29] Zetco Pty Ltd. v Austworld Commodities Pty Ltd. 2 FCA 84, 2011.

[30] Elwood Clothing Pty Ltd. v Cotton on Clothing Pty Ltd. FCA 447, 2008.

[31] Copyright Act 1968. (Cth)

[32] Liebowitz, S.J. and Stephen, E.M. (1995) Path Dependence, Lock-In, and History. Journal of Law, Economics and Organization, 11, 205-226.

https://doi.org/10.2139/ssrn.1706450 
[33] Schumpeter, J.A. (1934) The Theory of Economic Development: An Inquiry into Profits, Capital, Credits, Interest, and the Business Cycle. Transaction Publishers, Piscataway.

[34] Nikulainen, T., Raine, H. and Martti, K. (2008) Patent Citations Indicating Present Value of the Biotechnology Business. International Journal of Innovation and Technology Management, 5, 279-301. https://doi.org/10.1142/S0219877008001436

Submit or recommend next manuscript to SCIRP and we will provide best service for you:

Accepting pre-submission inquiries through Email, Facebook, LinkedIn, Twitter, etc. A wide selection of journals (inclusive of 9 subjects, more than 200 journals)

Providing 24-hour high-quality service

User-friendly online submission system

Fair and swift peer-review system

Efficient typesetting and proofreading procedure

Display of the result of downloads and visits, as well as the number of cited articles Maximum dissemination of your research work

Submit your manuscript at: http://papersubmission.scirp.org/

Or contact tel@scirp.org 